\title{
To enhance the teaching of linguistics colleges and universities using
}

\section{explore measures}

\author{
Tian Mingli \\ Qiqihar Medical University, Qiqihar City, Heilongjiang Province, 161006
}

\begin{abstract}
Language as human communication tools, its nature, structure and the application of the law, are the objects linguistics study. Linguistics is a basic subject in colleges and universities, aimed at improving students' understanding of language activity ability, application ability and analysis ability. From the point of linguistic teaching present situation, idea, curriculum setting, teaching material and teaching still exist more insufficient in aspects。 This is the focus of this discussion, but also enhance the effectiveness of language teaching needs to focus on analysis, correctly face, earnestly improve the breakthrough point.
\end{abstract}

\section{Introduction}

Linguistics in colleges and universities on the course goal setting, In modern languages knowledge systems for architecture, for the purpose of teaching system of linguistic knowledge, by the interest, ability, for the higher education stage of knowledge accumulation and cultural learning.

On the course content, linguistics and literature, grammar, pronunciation, vocabulary, pragmatic and practical writing related to various aspects such as, provide theoretical support for the related disciplines and analysis tools, is a basic application subject in university courses.

Face linguistics teaching problem, therefore, to improve teaching methods, teaching efficiency is a realistic teaching reform.

\section{Linguistics teaching colleges and universities}

As the linguistic focus on theoretical knowledge, language is the object of study, the regularity of language, basic terminology, language form principle is the main teaching content. In addition, the abstract noun, involving more linguistic teaching concept, it is difficult to use intuitive, image or figurative connected with real life and explain the citation, students need to understand and master the use of abstract thinking, which make the process of teaching and learning is boring, boring, lack of vitality, this is caused by the course emphasizes on the theory of subject characteristics of knowledge, on the other hand from the side to linguistics teaching put forward new topics, namely how the theory abstract the concept of knowledge, to develop effective teaching art, enhance the vitality and effectiveness of teaching in classroom teaching, so that students in learning theory knowledge, to overcome the psychological conflict Linguistics have a sincere interest in learning, so as to improve the teaching effect. At the same time, teachers' teaching methods, teaching concept and mode, there are people waking, defects, the linguistics teaching into a difficult to extricate self imprisoned, unable to keep pace with the generation of rhythm, can not reflect the characteristics of the times.

College has a strong ability of self management, but also the formation of personal interest and thinking characteristics of the more stable, so it has certain consciousness in learning, but the learning effect is influenced by individual learning intention. The characteristics of the theoretical 
teaching of linguistics are obvious, so that the majority of students are not willing to learn, thus affecting the overall cognitive level and teaching effect. According to the investigation data display, the university language class specialized student generally thought at present the linguistics is only a special course, is not big to the practical application and the specialized correlation discipline study function, involves the concept and the principle and the daily life relatedness is not obvious, does not have the explicit realistic value, therefore, the majority students pause regarding this schoolwork understanding in the passive study stage.

Although the humanities and literary elements are injected into the curriculum reform, it has not completely solved the difficulties in the teaching of linguistics, As a result of this intuitive emotional orientation, the basic theory of linguistics has been concealed, which leads to the weakening of the real intention of the subject, Causes the student to the application of linguistic meaning and development prospect of question and misunderstanding, linguistics is regarded as an optional subject, in the long term, inevitably lead to the decline of linguistics, language application ability of collective degeneration.

\section{The limitations of linguistics teaching in Colleges and Universities}

At present, the university language class specialty in Chinese and English two languages, all kinds of small languages have professional courses in the linguistics, in various professional plan, students is the main object of teaching language. Due to the particularity of language class professional, all need to attend all kinds of professional grade examination teaching object, contains more linguistic knowledge points in the test, therefore, the linguistics course design for language class professional students, is a foundational discipline, contains a large number of basic theoretical knowledge, need to attach importance to it. Linguistics confined to theoretical knowledge in the curriculum, boring, teaching process with stiff lectures and instill atmosphere, teaching outline on the lack of practical application plan, lead to most language class students of linguistics' interest of learning, the learning attitude of linguistics 。

In view of the present situation of higher education, the traditional teaching ideas and models still occupy a dominant position, and the teaching ideas of teachers and research institutions still follow the same course of preparing lessons, classes and homework, Lack of exploratory and innovative consciousness in the course design, teaching idea, pattern is too moderate, with regular classroom teaching, teaching infusion as the main way. The overall knowledge structure of language teachers is aging and the teaching skills are ignored, For language class teachers in colleges and universities lack of proper education and training mechanism, is the leading cause of linguistic teaching concept limited factor, Most of the language teachers have a good understanding of the teaching materials, and the linguistic theories seem to be solid, However, in the actual teaching process, there is a lack of understanding and flexible teaching ideas, the lack of a comprehensive understanding of the concept and theoretical knowledge of the professional field, Scripted, these are the disadvantages of conventional common in language teaching.

University linguistics on the teaching method is single, in addition to lecture and teach, almost no practical teaching link and at the same time. The teaching process tend to teacher speak students listen to the old model, In the whole process of teaching, teachers' teaching ideas is too conservative, the learning interest of the students has not been effectively developed, innovation consciousness, learning motivation in the vacuum state, resulting in linguistic teaching form, through the phenomenon of serious. Secondly, in the process of language teaching, teaching the application frequency of modern equipment is low, the traditional teaching aids, teaching materials and teaching ideas, learn to speak, as the main line, teaching evaluation activities seriously lags behind 
the progress of teaching, lead teachers do not understand the learning situation of students in teaching, teaching arrangement of teachers and students learning needs from each other, resulting in the weakening of the teaching activities of the explanation function. In addition, the language teachers in the teaching is too rigid, the lack of interaction and communication with students, but also lead to a decline in interest in learning, learning motivation, one of the reasons.

The first is that the teaching materials of linguistics are smaller, At present, the selection of the teaching materials of linguistics is mostly used in "Linguistics", The book was first published in the 80s of last century, which is in line with the linguistic background of the time, and played a positive role in the study and teaching of linguistics at that time, However, it is not fit for the current linguistic environment, and its theoretical system and the research results are not matched with the current linguistic research environment. Secondly, the content of the language teaching materials is lagging behind,Professor Hu Zhuanglin presided over the compilation of the linguistics course, and now there are nearly thirty years of time difference, In this process, the linguistic system produced a lot of new linguistic theories, many has academic value and research value and academic value of research results has not included in the book, Therefore, this teaching material is obviously not suitable for the development of modern linguistics. For students, linguistics textbook behind the times context, can only grasp the basic knowledge of linguistics and traditional, but not with the combination of the practical application in theoretical terms to the existing context of the concept and principle of fault, not a deep understanding of professional knowledge, is not conducive to professional learning.

\section{Measures to promote linguistic teaching}

Should be combined with students' cognitive characteristics of the setting of linguistics courses, considering the characteristics of language learning and teaching practice, the theoretical teaching and practical goals combining the teaching and research group established a high level of high-quality, for each branch and category in Linguistics and meticulous combing, the introduction of science, times and guidance courses decomposition. Such as decomposition of phonetics knowledge in specialized course teaching, the combination of pronunciation practice of phonetics in teaching and can effectively ease the phonetics teaching their own sense of monotony and overhead, but also the organic combination of theory and practice, to make the students learn phonetics related in the process of practice pronunciation abstract concepts and principles.

Such as decomposition of phonetics knowledge in specialized course teaching, the combination of pronunciation practice of phonetics in teaching and can effectively ease the phonetics teaching their own sense of monotony and overhead, but also the organic combination of theory and practice, to make the students learn phonetics related in the process of practice pronunciation abstract concepts and principles. This curriculum embarks from the relevance between course, broke the conventional teaching arrangement of each into a system in the teaching mode, Through enter and fusion, strengthened the basic course and specialized course, and give full play to the linguistic theory instruction function.

University education should stand in the forefront of basic education, lead the fundamental education development in the direction of the scientific, advanced and self-improvement, From this perspective, The idea behind problems common in higher education is not only a linguistic discipline, but an urgent problem to be solved. First higher education schools need to break the traditional ideas, want to have to the international education peer learning attitude and courage to learn advanced concepts in the field of education and introduce advanced teaching ideas, to strengthen the business skills of the teachers training. Second, universities should establish the 
perfect training mechanism, create opportunities and encourage teachers to participate in various kinds of advanced study and academic exchanges, encourage teachers take an active part in continuing education, the organic combination of in-service education and the duty education, make teachers self learning mechanism, enhance its awareness of self-improvement. Finally, in the process of teachers continuing education, pay attention to the theory with practice, pay attention to learning the actual effectiveness, from the ideas, concepts and ability to change the old teachers, teachers in colleges and universities from the inside to the qualitative change, so as to promote interdisciplinary, especially the teaching effectiveness of linguistics.

Linguistics lay particular stress on theoretical knowledge teaching, preaching is easy to fall into the erroneous zone, Therefore, innovative teaching methods can complement to a certain extent of the insufficiency of the teaching material arrangement, inspire students' learning interest and enthusiasm, thus improving classroom atmosphere, the quality of teaching in the teaching of linguistics. As in the teaching process, teachers can teach according to the arrangement of teaching needs scientific teaching and discussion teaching two ways, depending on the chapters content characteristics, carding related knowledge in advance and merging, Distinguished by teachers to put forward the corresponding discussion topic, so that the students as a group to consult, to discuss for the unit, On the one hand, is beneficial to form a relatively active classroom atmosphere, on the other hand, to a certain extent, dilute the monotonicity of theory knowledge teaching, make students' subjective initiative in the process of topic discussion to inspire, to generate interest in linguistics.

In addition, linguistics, teachers should make full use of modern teaching equipment, use of multimedia teaching courseware, Internet resources, it's best to abstract knowledge fusion to visual and audible visual audio and video materials, make linguistics theory knowledge teaching on the basis of the guarantee academic seriousness, realize the fun and vividness, seriousness, the height of the academic integration.

First of all, The need for education sector organizations linguistics experts and teaching and research of tertiary institutions team on current patterns of colleges and universities teaching linguistics, trends and needs to conduct a comprehensive and in-depth analysis and develop a scientific and rational multidisciplinary educational objectives. Secondly, curriculum development teams need to be integrated with adwords development trend, the existing research results, new adwords theories, concepts and principles for a comprehensive integration of stringent academic spirit prepared in conformity with the requirements of the times for an Adwords teaching materials.In addition to increase the supplementary information related to the preparation, linguistic teaching materials include teacher's book, extending students ' independent reading and study books, designed to develop the autonomous learning ability of college students, to broaden the field of professional, comprehensive and innovative linguistic series.

\section{Tag}

So far, the linguistics teaching situation is not optimistic, the limitations of the traditional teaching mode and restriction has been especially acute in the process of language teaching. In order to enhance the effectiveness of teaching and linguistics, making linguistics for language class professional learning to promote role, need to strengthen self learning, language teachers improve teaching concept, teaching method, at the same time need higher education course in organizational planning as soon as possible and adapted to the times, organized the compilation of textbooks, to enhance performance and lay a solid foundation of Linguistics in university teaching. 


\section{Acknowledgement}

Project name: Experimental Study on the Influence of Mother Language upon Second Language Acquisition

Project number:QYSKL2015-08

\section{Reference:}

[1] Zhao Lin. Improve the teaching strategies of linguistics in colleges and universities [J]. Language Construction, 2013, 35: 14-15.

[2] Zhou Hui. On the reform of linguistics in colleges and universities [J] .Development, 2015, 15: 148.

[3] Sha Sha. On the reform of linguistics curriculum in colleges and universities [J]. Curriculum Education Research, 2014, 23: 38-39. 